\title{
A study on the cultural connotation of choreographer teaching in colleges and universities
}

\author{
Fan Yang \\ Art college of xiamen university $\quad 361005$
}

Key words: dance; choreographer teaching; culture; cultural connotation

\begin{abstract}
Dance is a kind of cultural carrier, and dance creation is to carry forward the culture, the essence of each created works is the cultural connotation. Dance choreographer course is to teach students choreography skills, choreography skills is a kind of rational creation, but also is only a level of creation, which also need to use such as music, stage design, soundbox, props, clothing, makeup, stage effects and so on, supporting the dance itself. The most important thing is to have new ideas and enough ideas to make the work cultural, different from other dance, form the most unique part. Cultural connotation is the soul of dance, which can not only make dance full of charm and color, but also convey spiritual taste. Dance is the carrier to show the spiritual homeland and the blood of the Chinese nation. Dance and culture are closely linked.
\end{abstract}

\section{Introduction}

The central Committee of the communist party of China on deepening the reform of the cultural system to promote the development and prosperity of socialist culture in a number of major issues pointed out that "Culture is the blood of the nation and the spiritual homeland of the people. In the course of the civilization development of our country for more than 5,000 years, the people of all ethnic groups have been closely united and constantly striving for self - improvement, and have jointly created a Chinese culture with a long history and profound breadth, which has provided a powerful spiritual force for the development and growth of the Chinese nation and made indelible and significant contribution to the progress of human civilization." Dance is the communicator of culture, dance creation can promote the culture, carry on the culture. The core of every dance work is cultural connotation. The main content of choreography course is to teach choreography methods, choreography skills is a kind of rational creation, but also is only a level of creation, which also need to use such as music, stage design, soundbox, props, clothing, makeup, stage effects and so on, supporting the dance itself. The most important thing is to have new ideas and enough ideas to make the work cultural, different from other dance, form the most unique part. Therefore, the promotion of cultural connotations is that every creator should keep learning and persistence. In classroom teaching, the most effective way for teachers is not only to direct students to dance, but also to make students develop accumulated habits.

\section{Reasonable and effective teaching method}

It is very necessary to strengthen the education of cultural connotation, although it is only a part of the choreography course, so effective teaching means are especially important.

\subsection{Interest teaching method}

As the saying goes, interest is the best teacher, cultivate students' interest in culture is the first. Teachers should understand the interests of students, set out from their interests, give them what they want, and make students curious about the accumulation of cultural knowledge. For example, if students like reading, recommend some books to him, or ask students to recommend their favorite books to teachers. If students like music, leave them some music-related assignments to collect 
different types of music. Interest is not achieved overnight, it also need reasonable guidance, take interest as a starting point, let students unconsciously accumulate knowledge in happiness.

\subsection{Guide teaching method}

Interest teaching method is the most effective method in the primary stage of choreography teaching. Students need other methods to broaden their horizons after they fully understand this method. Teachers should guide teaching on this basis. At the beginning, the teacher can lead the students to collect knowledge together, then gradually reduce the teacher's participation in it, and let the students develop themselves while collecting. The most important thing in guide teaching is to let the students accumulate knowledge and combine them into their creative works. In the early stages, students are enthusiastic because they can create what they think. But in fact, their idea is often too simple to make the work less appreciative. Teachers need to give comments at the first time, point out the problem, and give students a good direction of guidance, and then let the students strengthen the understanding and mastery of culture through reflection, and gradually achieve the use of learning, fully absorb.

\subsection{Discussion teaching method}

When knowledge is increasing, we should pay attention to let students learn to communicate, which is more conducive to the mastery of new knowledge, and they can aware of their own shortcomings in the discussion. Discussion method can be between teachers and students or between students. Of course, we need to collect relevant information in the early stage, and learn knowledge from each other when communicating, so as to make up for their shortcomings. With the deepening of the discussion, students may find that they are also interested and advantageous in a certain aspect, and will inspire their desire to learn. Communication can also learn other people's good learning methods, let oneself accumulate more knowledge.

\section{Methods of strengthening accumulation of cultural connotation}

The main methods of cultural accumulation are as follows: reading, film and television works, visits and so on.

1. Reading, there are a lot of books, there are no limits, anything that is interesting can be read, literature, history, politics, astronomy, geography, religion, dance, music, etc. There are endless good books to taste. Although there are many books, you should read them in a targeted way, and clearly know where your interests are, so that you won't waste your time.

The following broad categories of books are recommended: quintessence book, famous works, classic or representative book. The quintessence book, is similar to the most beautiful prose, the most worthwhile places to visit, the most delicious food beauty, the world's most beautiful scenery, national history, world history and other categories of books. Because the content of these books is selected from other books carefully, through reading this kind of books, can let us learn all kinds of knowledge very quickly, feel the beauty of the text, feel the beauty and characteristics of every place. Some books has the author introduction and appreciation, which allows us to have a deeper understanding of the author and create a more systematic grasp of the skills while enjoying the beauty of the text. Representative book refer to very typical, authoritative masterpieces, such as $\mathrm{Lu}$ Xun's " Call to Arms", " Wandering", " "Ascends towards Flowered Evening", Shakespeare's four tragedies, Zhu Ziqing, Bing Xin's essays, "Fortress Besieged", " The Ordinary World", " To Live", " Notre Dame cathedral", "Pride and Prejudice", " The Unbearable Lightness of Being", and so on. It has to be mentioned that the Four Great Classical Novels, especially the " Dream of the Red Chamber". They are the treasures of Chinese culture, both historical and literariness are very excellent. It is not difficult to make a unique and literary dance work by reading these excellent classical works, bringing them onto the stage, creating and arranging them carefully. For example, the stage play A Dream of Red Mansions is an excellent dance work formed by adaptation. 
2. Watch film and television works, including movies, television, drama, musical, song and dance drama and other forms. Film and television works is more intuitive than books, they can give people a more profound feeling, coupled with the actors to shape the image of the charm and star effect, can deepen the impression of viewers. For example, "Titanic " let us admire the greatness of love and the impermanence of fate, "The Shawshank Redemption" let us understand the power of perseverance and determination, "Three Idiots" let us know what pure friendship is, "Twelve beauties of Jinling" let us understand the humanity and patriotism of the ordinary people of the the anti-Japanese war period, "Love Is Not Blind" Let us feel the sweetness of love in a relaxed and pleasant atmosphere. A large number of film and television works enrich our spiritual world, and let us know the culture and customs of different countries. Let us have an awe of history and have a comprehensive understanding of the characters' psychology, geographical environment, religious belief and so on. While watching film and television works, we should also pay attention to the change of clothing. Although film and television works are all interpreted by contemporary people, historical culture and traditional costumes will not change. The style of clothing also plays a great role in the creation of the works. The music in the film and television works is also very nice, very consistent with the era of the film and television works, also has the geographical characteristics and ethnic customs, a good music can inspire choreographer's creation inspiration.

\section{Conclusion}

Culture is the source of good dance, only by constantly consolidating the foundation and accumulating culture, can we achieve the result of quantitative change to qualitative change. Any excellent dance creator whose core competitiveness comes from the accumulation of culture. When a person understands history, geography, literature, music, dance, then he can create a vivid dance. Dance works without cultural connotation are like empty shells without soul, which cannot resonate and will not be remembered by people. Culture as the carrier of dance, is very important. Therefore, we should accumulate culture, accumulate steadily, hold on for a long time, will create excellent dance works.

\section{References}

[1] Wei Sunlu. Innovation and cultural connotation in choreography teaching in colleges and universities[J]. Heilongjiang Science,2017,8(01):44-45.

[2] Jiang Yi, Zhang Bi. A study on the cultural connotation of dance choreography teaching in colleges and universities[J]. Art Research,2012(03):40-41.

[3] Tian Yuan. Research on the improvement and practice of the dance choreographer teaching quality in colleges and universities[J]. Journal of Jilin TV \& Radio University,2017(11):74-75.

[4] Zhu Qiutao. Analysis on the cultivation of creativity in dance choreography teaching in colleges and universities[J]. Reading and Write Periodical,2017,14(06):28.

[5] Yin Ke. Cultivation of creativity in dance choreography teaching in colleges and universities[J]. Literature and Art for the Populace,2014(23):245-246. 